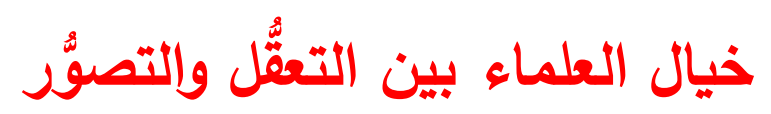

SCIENTISTS' IMAGINATION BETWEEN REASONING

\title{
AND VISUALIZATION
}

\section{An article on the philosophy of science}

\section{أ.د. / أحمد فُؤاد باشُّا}

\section{www.afbasha.com}

The ability to engage oneself in constructive philosophical imagination and to use the scientist's imagination are among the most significant characteristics a scientific researcher should have, exactly like the painter when he visualizes something or someone out of the characteristics given to him. The history of sciences often emphasizes the importance of such characteristics that can lead to scientific discoveries of facts of phenomena prevalent in horizons and souls. Facts and ideas are per se inanimate; it is the imagination that gives them life. Faraday, with his known scientific sense and methodical imagination, used to say that he nearly could perceive the electromagnetic fields before Maxwell could put them into mathematical formulas. Cognitive characteristics or faculties as such are only possessed by the talented and they play an important role in achieving and developing scientific findings through refining the scientist's talent and sensing the laws of nature.

\section{" نائب رئيس جامعة القاهرة الأسبق، وأستاذ الفيزياء وتاريخ العلوم.}

أ.دا/ أحمد فؤاد باثـا

(خيال العلماء بين التعقُل والتصوُر) 


\section{الخيال المنهجيّ والتفكير العلميّ:}

إن من أهم سمات الباحث العلمي الجيد أن يكون متمبًِِّا بقدر من الفضول الفكري، والمقدرة على التأمل الفلسفي البناء، واستخدام خيال العالم وإحساسه الحسيّ في كثف الحقيقة العلية دون تجاوز للواقع، وفي رسم الصورة العلية

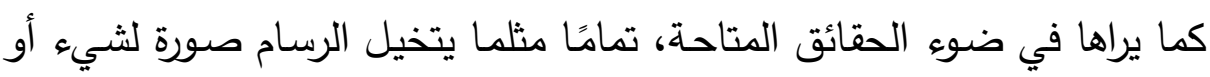

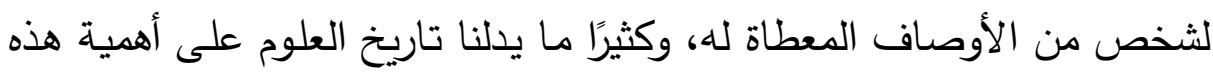
الصفات في العثور على كثوف علمية لحقائق الظاهرات المنبثة في الآفاق وفي الفي الأنفس.

وكان 》فـاراداي《، بحاسته العلميـة وخياله المنهجي، يقول إنه يكاد يرى مجالات القوى الكهرومغناطيسية، وذلك قبل أن يفرغها 》ماكسويله في قوالب لبه

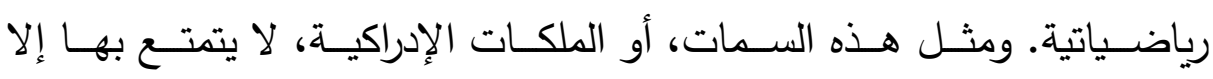

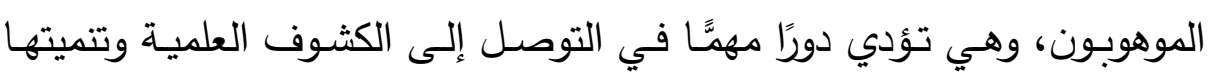
بصقل موهبة العالم واستثعاره لقوانين الطبيعة. وقد وصف أحد أصدقاء فاراداي لمعان بصيرته التي أشرنا إليها فقال: (إنه ؤهب ما لم يوهبه إلا علماء قلائل، حتى لكأنها كان يرى السلـك يقطع خطوط القوى، ويستشعر التيار الكهربي ينبض في داخل السلكه، وما أبلغ تصوير أينشتين لخيال العالم الموهوب عندما قال: 》الفيزياء محاولة للقبض على ناصية الحقيقة كما هي في النكر، دون نظر

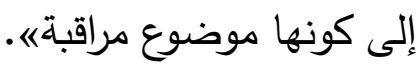

ويؤثر عن الفيزيائي الأيرلندي البارز "جون تندوله (1893-1820)،

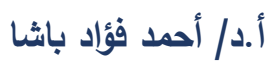

(خيال العلماء بين التعقُل والتصوُر) 
الذي اشتهر بمؤلفاته العميقة في فلسفة العلوم، قولهـ: \الخيـال هو المهندس الذي يضـع تصميم النظريـة العلمية، مستعينًا بما تنقله التجارب والملاحظات الاقيقةه. وقال أيضًا عن أهمية الخيال في العلم: ״كان انتقال نيـوتن مـن تفاحـة سـاقطة إلى قـر سـاقط، عمـلًا مـن أعمال الخيال المتأهب. ومن بين الحقائق الكيميائية استطاع خيال

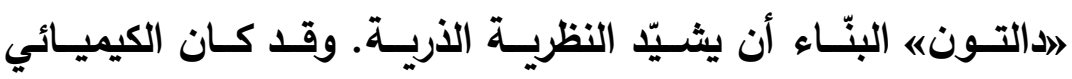
والفيزيائي الإنجليزي 》همفري دافيه يتمتع بموهبة تخيلية غزيرة. أمسا 》فـاراداي《 فقد مـارس هذه الموهبة على الدوام، حيث كانـت هذه المخيلـة سـابقة ومصساحبة ومرشـدة لجميـع تجاربـه، وتعزي قدرتـهـ وخصوبته كمكتثف، إلى حدٍ كبير، إلى القوة الا(فعة للخياله. ولا تقتصـر أهميـة الخيـال المنهجي على إرشـاد العلمـاء إلى وقائع جديـة فحسب، بل إنه يحثهم أيضًا على بذل جهود جديدة، ذلك أنه يتيح لهم لارؤيسةه ما يمكن أن تتمخض عنه هذه الجهود من نتائج، فالوقائع والأفكار في حد ذاتها ميتة، والخيال هو الذي يهبها الحياة. ولكن الأحلام والتخيلات ليست سوى أوهام عقيمة ما لم يحولها »العقله إلى أغراض نافعة، ويجب على العلماء أن يختزلوا تلك الأفكار المبهمة - التي يقتصونها كلما طاف بهم الخيال - ويحولوها إلى قضايا وفروض علمية محددة.

وقد حلّل الفيلسوف الأمريكي ״جـون ديـويه (1859-1952) التفكير العلمي الـواعي، ولفت الأنظـار إلى بعض السـمات العلميـة للتفكير الإبـداعي 
المنتج، وحبّذ ما سمّاه بالتفكير التأملي المنظم reflective thinking، أو ما نسميه 》بالخيال المنهي《، الذي يعني تقليب موضوع ما في الذهن من جميع جوانبه بطريقة مرتبة منهجيًا، وهو بهذا يختلف عن ترك الأفكار تمرح في الذهن كما تثاء دون تحكم في توجيهها نحو قضية محددة. وبالرغم من أن الخيال المنهجي هو أحد مصادر الإلهام في البحث عن

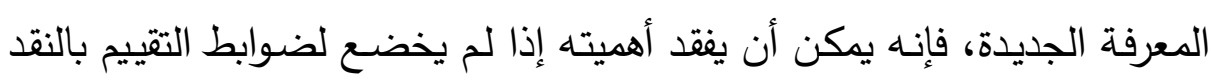

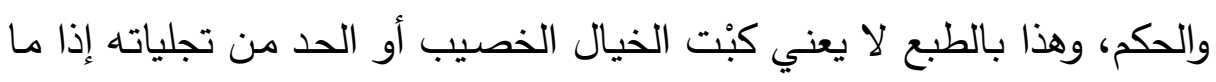
اقتصر على تمكين الباحث العبقري من التجول في ظلمات المجهول، عساه

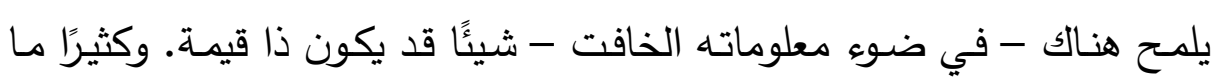
يتضح لهذا الباحث العبقري، بمجرد الخروج بخياله من هذه الظلمات، وعرضه لهنه

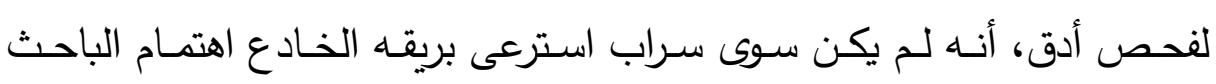
وانتباهه.

ومهما كان مصدر الفروض التي يطرحها العلماء لتفسير ظاهرة ما، فقد

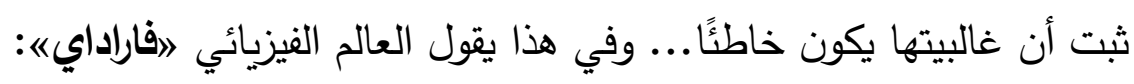
"امـا أقل مـا يعرف الناس عن تلك الأفكار والرؤى والنظريـات التي طافت بذهن الباحث العلمي وخياله، وسحقها في صمت وكتمان بنقده

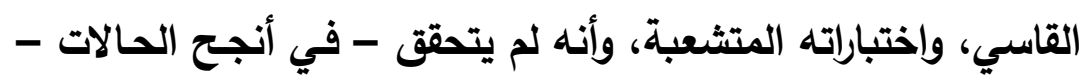

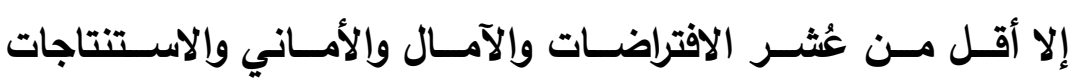
التمهيديةه. 
وليس هناك من شك في أن كل باحث علمي متمرس يؤيد هذا القول. بل لقد ذهب 》دارونه إلى أبعد من هذا حين قال:

القد كنت أسعى جاهدًا كي يظل ذهني حرًا في التخلّي عن أي فرض

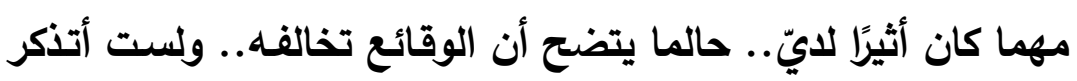

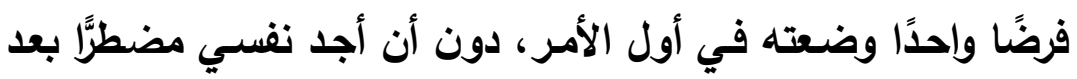
وقت ما إلى التخلي عنه، أو إلى تعديله إلى حد كبيرهـ ويقول 》بفردج) في كتابه 》فن البحث العلمي):

"اليس هناك مـا يدعو إلى الخوف في الوقوع في الخطأ، بشرط أن يعرف المرو هذا الخطأ في الوقت المناسب.. ويصحّحه.. فالعالم الذي

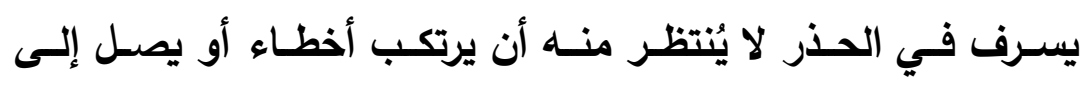

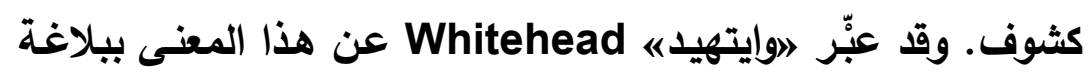
حين قال: 》الخوف من الخطأ مقبرة للتقدمه. وقال السير "همفري دافي《: لقد أوحى إليّ الفشل بأهم كشوفيه.

على أنه من المفيد أحيانًا في البحث العلمي عن أفكار مبتكرة، التخلي عن

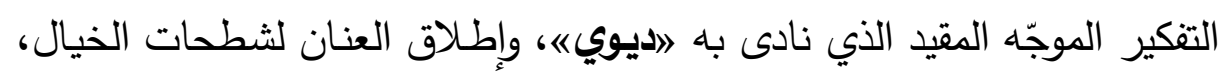
والاستغراق في الأحلام، ومتابعة تعاقب الأفكار عند ظهورها، وتركها تتكون لهانه وتتفرع على سجيتها حتى تتمخض عن بعض النتائج النافعة. وهكذا نستقرئ من مذكرات العلماء الفاقهين وخبراتهم مدى أهمية الخيال 
المنهجي في تحقيق نجاحاتهم، ومدى معاناتهم في اقتناص أفكارهم الصـائبة وصياغتها في فروض وقوانين ونظريات علمية جديدة.

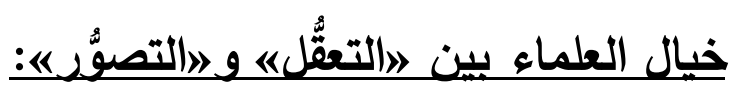

يعلم أهل الاختصـاص في مجال فلسفة العلم ومنـاهج البحث العلمي أن تحصيل المعـارف العلميّة نشاط مقصـود يهدف الباحث من ورائـه إلى دراسـة ظواهر معينة وقضايا محددة يعكف عليها ويتناولها بالملاحظة الدقيقة، وبالتحليل المنطقي، مسـخدمًا في ذلك منهجًا يتفق وطبيعـة موضـوع البحـث، بغرض التوصل إلى قوانين عامة، أو حتى مقولات أو نظريات، تفسر اطراد الظاهرات المختلفة، وتدل على احتمالات الإفادة العلمية من تطبيقاتها. ومن ثم فإننا نحتاج في اللغة العلمية إلى الصياغة الدقيقة التي تكتسب فيها الألفاظ المستخدمة في تعريف المسميات والمصطلحات والمفاهيم معانيها التي تحدد ما يثار في الذهن عند سماعها من أفكار وتصورات ومشاعر، وما يشار إليه من أشياء في عالم الواقع. بعبارة أخرى، تكتسب اللغة العلمية دقتها من مدى تعبيرها عن الحقائق العلميـة، إمـا بوصفها تطابقًا للواقع الموضـوعي، وذلك بإطلاق 》الواقـعه لفظًا على الأمور التي يمكن التحقق منها على نحو يقرّ الجميع، أو تطابقًا لقضـايا ذهنية ليس لها مسمّيان في الواقع، مثل قضـايا 》الواقع الاقتراضسي، أو بعض قضـايا علم الرياضيات للأشياء كمـا هي في ذاتها، مثل الانتقال بالأعداد من المحسوسات إلى المجردات التي يستطيع العقل أن يكوّن عنها أفكارًا بدون أن يكون لها معدود تتطبق عليه؛ كما هي الحال مع 》الصفره الذي لم تظهر فكرته 
إلا في مرحلة متأخرة عن الأعداد المعروفة، ومع »الأعداد السالبةه، و الأعداد التخيليـةه، وغيرها. وينبغي في هذا السياق أن يستقر في الأذهان أن صدق قضـايا المعرفة العلمية وقوانينها لا يعني بلوغ اليقين المطلق في صحتها، وإلا ترتب على ذلك أن تكون نتائج العلم مطلقة الصدق واليقين في جميع الأحوال، الأمر الذي لا يتفق مع طبيعة العلم ذاته، ومهع استمرارية مسار تطوره المشاهَد من إعادة النظر في تراكم الاكتثافات العلمية التقليدية. من ناحية أخرى، يوجد من بين قضـايا العلم التخيلية ما يقوم عليها البرهان العقلي القاطع، ومع ذلك يكلُّ العقل عن تصوّرها، حتى بعد الحساب؛ ذلك لأن عقولنا خُلقت عـاجزة عن تصدّر كثير من الأشياء، ولكنها تستطيع أن تحكم بوجودها من طريق البرهـان العقلي القاطع، فالتصوُّر غير التعقُّ، فقد يكون بالإمكـان أن يُعقل شـيء مـا، بينمـا يستحيل تصـوره؛ لأن التعقُّل يعتمـد على بديهيات أولية يأخذ العقل في ترتيبها وتركيبها، واستنباط بعضـها من بعض، وبناء بعضها على بعض، فيصل إلى حكم عقلي قاطع قد لا يستطيع تصوّره، رغم أنه لا يشكّ في صحته. والعلم الحديث اليوم يقرّ هذه الحقيقة عن الفرق بين إمكان تصوّر الثيء وإمكان تعقّله، فلا يبالي بعجز العقل عن التصوٌّر، ويعتمد على التعقّل وحـده، لأن الحقـائق العلميـة أصـبحت، في مجالاتها، وكمياتهـا، وأعدادها، فوق التصوّر، ولكن العلماء يحسبونها ويُعرِفونها ويحكمون عليها عن

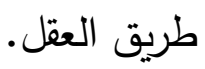
وإن شئنا مثالًا يوضـح ملكة الخيال المنهجي عند عباقرة العلماء، وقدرته 
على تعقُل الأثياء أو تصوُرها، فإننا نجد - على سبيل المثال - كيف أن العلوم

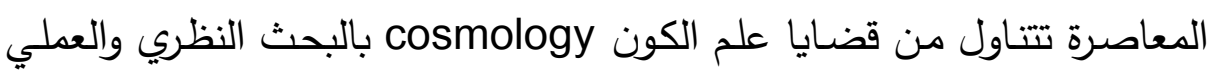

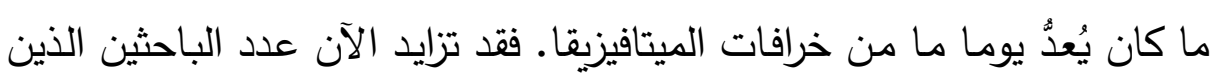

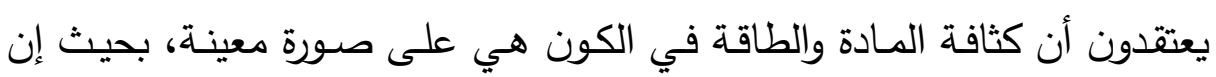

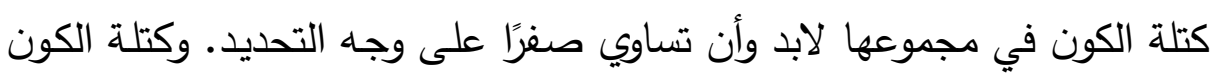
تُعتبر من المعطيات الفيزيائية التي يمكن تقديرها عن طريق القياس العلدي فئسي

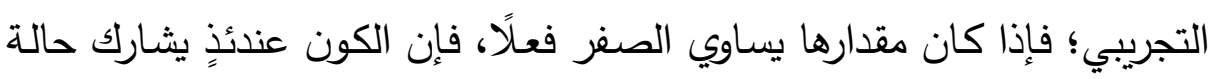
الفراغ التام في خاصية 》انعدام الكتلة)، وقد ظهرت حديثًا نظرية جريئة تنطلق من هذه الفرضيات لتعتبر الكون على صورة تقلبات كوانتيَّة حول الفراغ، وهي

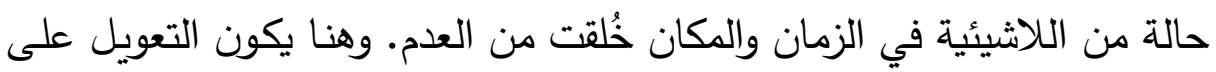
التجربـة ضـروريا للحكم في إحدى قضـايا ما وراء الطبيعة؛ فعن طريق قياس كثافة المادة في الفراغ يمكن معرفة مدى صحة هذه النظرية العلمية، علما بأن

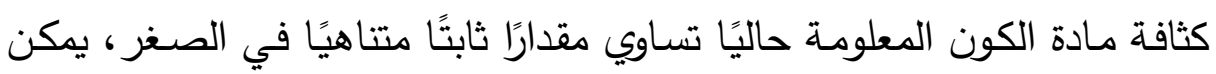

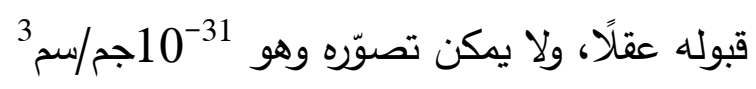
من زاويـة أخرى في علم الكون، تتعلق بأصله ونثأته، يقول العلهـاء إن

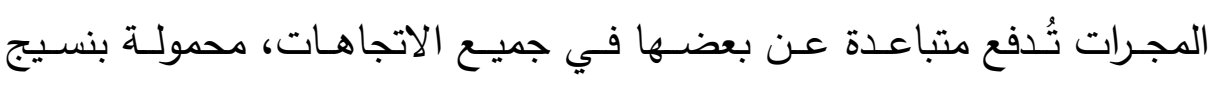
״زمكانيه يكبر بانتظام. وقد بات واضحًا بالدليل القاطع أن الكون يتمدد.

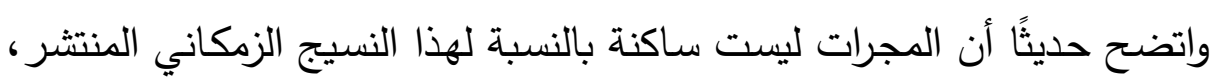

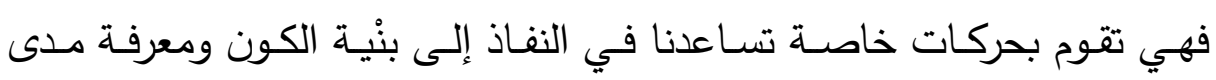


التقلبات الكوانتية في كثافة مادته. وما توصل إليه الباحثون عن هذه الحركات يوحي بأن المـادة الكونية تتكتَّل مـع بعضـها بمقاييس كبيرة لا يمكن تصـورها، فتعطينا معلومات عن الأحداث التي جرت في بواكير نشأة الكون، وقد تجيب هذه الحركات أيضًا عن سؤال حول النهاية الأخرى للزمن: فهل سيستمر تمدد الكون؟ أم أن قوة الجاذبية سوف توقف هذا التمدد في نهاية المطاف، أو حتى تعكسه بحيث ينهار الكون ثانية ويعود إلى كثافته الأولية؟ لهذا ينهمك الباحثون حاليًا في رسم أنموذج للجريان الكوني باستخدام أحدث التقنيات، وقد ظهر لهم بالفعل من النتائج والبيانات ما يجعلهم يتعاملون مع النظريات السائدة في هذا المجال بحذر شديد.

أيضًا، من أهم الإسهامات العلمية التي جذبت اهتمام العلماء حديثًا، ويؤدي فيها الخيـال المنهجي دورًا أساسيًا، تلك النظريـة التي استحدثها العـالم العربي

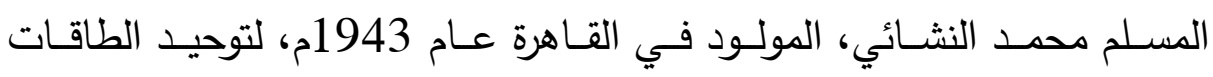
الأساسية في إطلار تصميم واستكمال نظريـة النسبية لأينشتين. ونظريـة التوحيد هذه تعالج في أحد جوانبها ظـاهرة تأثير 》القوى" على الأجسـام في الزمـان والمكـان عـن طريق الملاحظـة المباشـرة لتـدافعها وتجاذبهـا أمـام أعينــا. وهـي الظـاهرة التي بـدأها علمـاء الحضـارة العربيـة الإسـلامية بتحديــ أنـواع الحركـة وأوصافها، على نحو ما جاء في كتب »الثفاء《) لابن سينا، و 》التحصيل《 لابن المرزبـان، و 》المعتبر في الحكمـةهي 》لابـن ملكـا البغدادي)، وغيرهـا، ثم جاء »اسحق نيوتنه ليصيخ قوانينها على أساس استقلال المكان عن الزمان، وأعقبه 
أينشتين الذي أوضح أن الذي يجب اختبار صحته بالتجربة العلمية ليس القوانين العلمية، وإنما هي طريقتنا في التفكير.

فإذا كانت قوانين نيوتن قد نجحت نجاحًا باهرًا في تفسير حركة الكواكب حول الثمس، فإنه قد توجد قوانين أخرى مبنيّة على فروض مختلفة وتنجح أيضًا

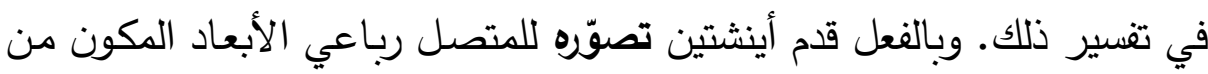
اندماج المكان والزمان اندماجًا تامًا يختلف عن أيّ منهما في حالته الدفردة، وهو

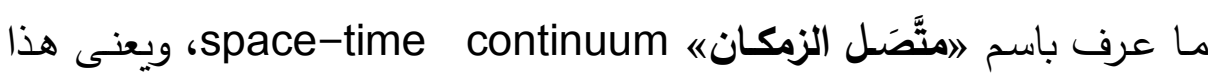

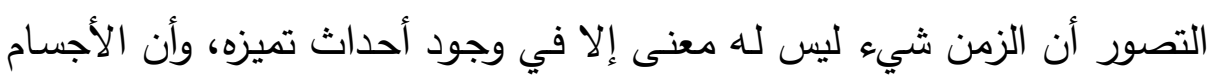

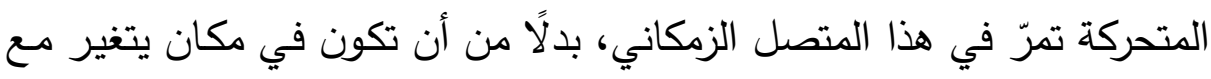

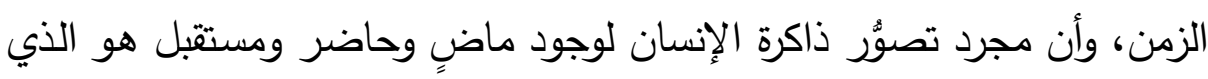

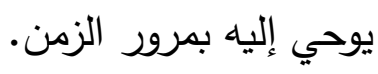

لكن هل الكون رباعي الأبعاد حقًا؟ أم أن هناك احتمالًا لأن تكون أبعاد

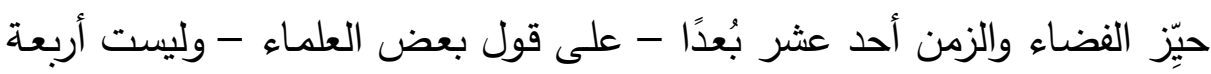

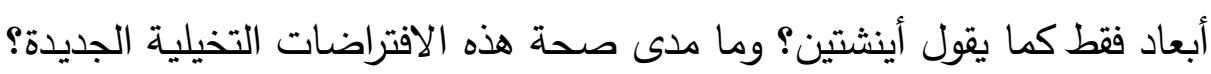
وإذا كان هناك من ينتظر الدليل القاطع على صحتها بالتجربة والبرهان، فإنها بكل تأكيد قد عملت على زعزعة أفكار كان يُظن أنها ثابتة حتى عهد قريب. ويلتقط عالمنا 》النثائي《 بداية خيط جديد لفكرة علمية جديدة، معتمدًا على أن العبرة في نجاح التفسير العلمي لقضية ما 》بالفكرة الصائبةه، وليس بالقانون العلمي مهما بلغت درجة نجاحه. ويقدم النشائي نظريته لاستكمال التصور الذي 
بدأه الإغريق والمسلمون، وطوره نيوتن وأينشتين، فيقول: "إن أينشتين صاحب

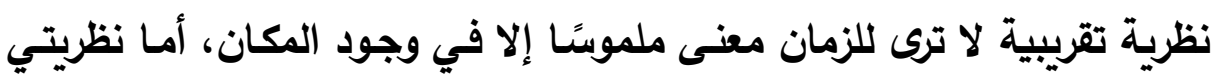

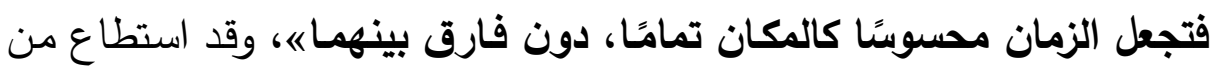

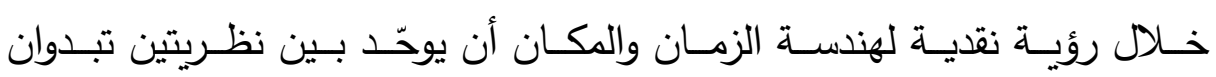

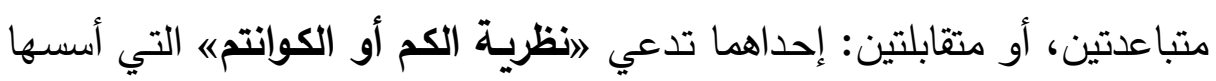

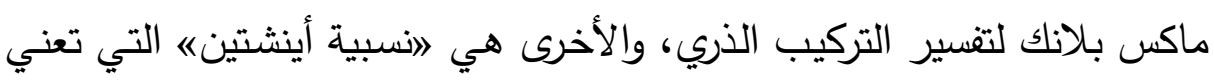

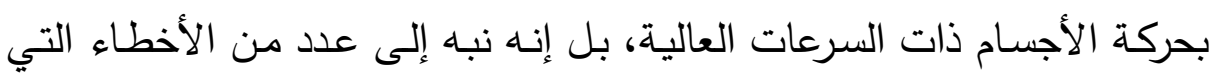
وقع فيها بعضهم، مثل 》بريجوجينه Prigogine الحائز على جائزة نوبل عام 1978م، و وستيف هوكنجز "S. Hawkings الذي كان يعمل معه النشائي في القسم نفسه بجامعة كمبريدج. وللنشائي آراء أخرى في مجالات متعددة تثمل نظريـة الفوضى، والثقوب

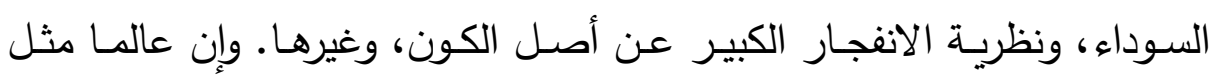
النشائي، تقوم أفكاره العلمية الجديدة على هذه الدرجة العالية من التخيل الدنهجي

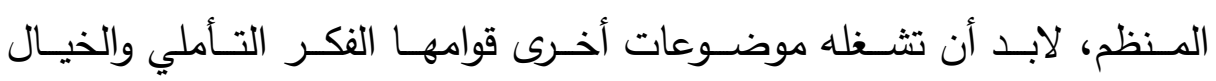
الخصيب، فحديثه عن الفراغ يتجاوز حدود الفلسفات المثالية والواقعية، ويرقى إلى أقوال بعض الصوفية، وخاصـة فيما يتعلق بمعنى الوجود والعدم، وتصوره

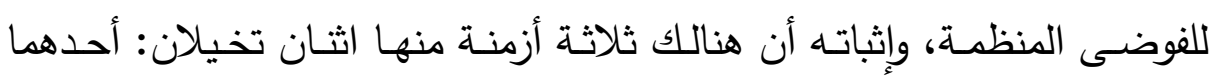
يسير إلى الأمام، والآخر إلى الخلف، وقوله إن 》التداخله interference هو تداخل للمعلومات، وليس تداخلًا للأجسام، وغير ذلك مما يحتاج إلى خيال العالم 
المنهجـي أكثر مـن خيـال الثـاعر، والموسـيقى، والأديـب الروائسي، والفنـان التشكيلي.

والواقع أن كثيرًامن فروع العلم المعاصر قد وصلت إلى مرحلة تتميز فيها

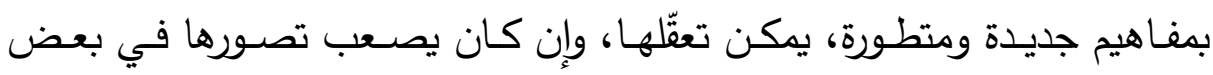

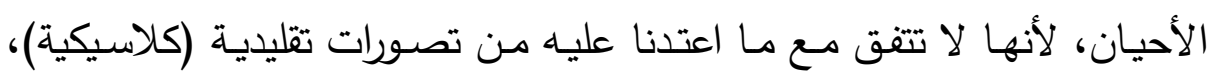

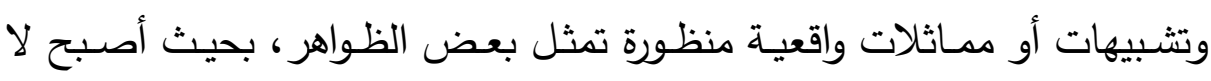
يمكن التعبير عنها إلا بمعادلات رياضياتية وصياغات ذهنية. وفي هذا السياق الذي يتعانق فيه الخيال المنهجي ميع الواقع الفيزيائي، توالت النظريات الكبرى

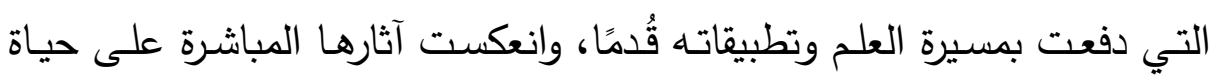
الناس وفهمه لطبيعة الكون الذي يعيشون فيه.

\section{نماذج لمفاهيج علمية تخيلية:}

\section{1- إثعاع الجسم الأسود:}

في بداية القرن العشرين اتضح للفيزيائي الألماني ״ماكس بلانكه أنه يمكن

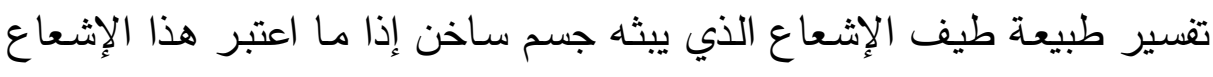

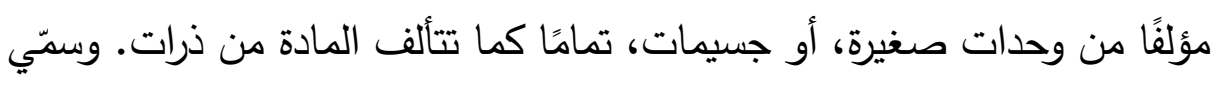

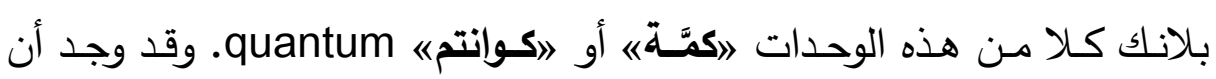
طيف الإثعاع الحراري الذي يعتمد بثدة على درجة الحرارة يعتمد بدرجة أقل

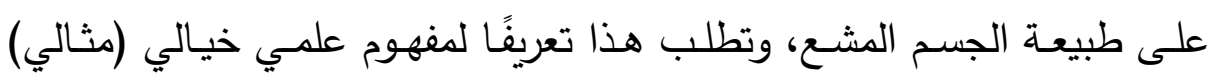


يسمى 》الجسم الأسوده، وهو الجسم الذي يمتص كل الإشعاع الساقط عليه ولا يعكس شينًا منه، ومن ثم فهو يعتبر الحالة المثالية للجسم الأسود العادي الذي يمتص معظم الضوء الساقط عليه فيبدو أسود.

وكـان لابـد من تحليل النتائج العملية لمنحنيات الإثـعاع الحراري للجسم

الأسود، ومحاولة استخلاص القوانين التي تصف السلوك العملي لهذا الإشعاع. وأمكن اعتبار أشعة النجوم، بما فيها الثمس، في حالة اتزان حراري مع الغازات الساخنة التي تتكون منها الطبقات الخارجية للنجم، ومن ثم يمكن تطبيق حالة إشعاع الجسم الأسود عليها لتقدير درجة حرارتها، ومعرفة متوسط الطول الموجي الأعظم للإشعاع الصادر منها.

كذلك توصـل بلانـك إلى قـانون يتفق تمامًا مـع منحنى الإشـعاع الحراري للجسم الأسود، وتقوم فرضيته في استتتاج قانونه على أنه أدخل لأول مرة في تاريخ الفيزياء فكرة اتكميةةه الإشعاع quantization of radiation، وظهر في القـانون مقدار ثابـت أصـبح يعرف الآن باسـم 》ثابــت بلانـكـ، وهو مـن السمات الأساسية لعلم الفيزيـاء الحديثة. وكان من أهم علامـات نجاح نظريـة الكم، أو الكـوانتم، أن أسهـت في فهم بنْيـة الذرات على أسـاس أنـه لا يمكن للإلكترونات أن تشغل إلا مستويات طاقة معينة ومحددة بدقة حول النواة، ويمكن للإلكترون أن يقزز من مستوى طاقة إلى مستوى آخر ، وأن يبث أو يمتص الكم المناسب من الطاقة عندما يفعل ذلك، ولكنه لا يستطيع أبدًا القفز إلى حالة بينيّة متوسطة. واستطاع أينشتين في عام 1905م أن يفسر انبعاث الإلكترونات من 
سطح معدني بتأثير الضوء على أساس هذه النظرية، وكان هذا هو الإنجاز

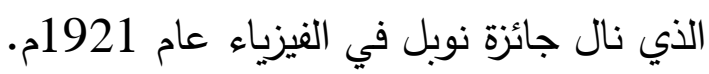

\section{2 -2 الطبيعة الازدواحية للمادة:}

استطاع الفرنسي 》دي بروي" de Broglie أن يوفق بين وصف أينشتين لطبيعة الضوء الكمية (الكوانتيةه الجسيمية، ووصف السابقين لطبيعته الموجية، فحدد العلاقة التى تربط بين الخاصيتين باعتبار الضوء ذا طبيعة مزدوجة، فهو جزئيا يبدو كأمواج، وجزئيا يسلك سلوك الجسيمات. وقدم 》دي برويه وصفا خياليًا مفـاده أن لكل إلكترون (جسيمي) موجـة تترافق معـه بطريقـة مـا وتوجـهـ حركتهـ، وأن مسـتويات الطاقـة المسـوح بهـا للإلكترون في الذرة تتطـابق مـع مدارات فيها عدد محدد من أطوال الموجات مثبتة حول النواة. ولا تزال نظرية ازدواجية جسيم- موجة تمثل إحدى نقاط الغموض في نظرية الكم، فهي ترتبط بمفهوم عدم يقين الكم، بمعنى أنه لا يمكن لأي ملاحظ أو مراقب أن يحدد بدقة مطلقـة كـلا من موقع الجسيم وكميـة تحركه في اللحظـة نفسها. فكلما ازدادت دقة تحديد موقع الجسيم نقصت دقة تحديد كمية تحركه. وقد كان الفيزيائي الألماني 》فيرنر هيزنبرجه أول من لفت الأنظار إلى 》عدم اليقين" uncertainty، باعتباره مظهرًا أساسيًا من المظاهر الطبيعية للإلكترون

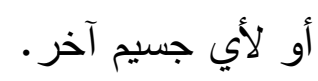

أ.د/ أحمد فؤاد باثـا (خيال العلماء بين التعقُل والتصوُر) 


\section{3-3 قطة اشرودنجري:}

من طريف ما يروي حول المفاهيم العلمية الخيالية أن الفيزيائي النمساوي 》شرودنجر طرح في عام 1935م تجربـة فيزيائية تخيلية شبهها بقطة وضعها مجـازًا في صـندوق، ووضـع معهـا قـارورة سـمّ، فهـي في حالـة تراكب الحيـاة والموت، ولا يمكن معرفة ما إذا كانت القطة حية أو ميتة حتى يفتح الصندوق. وبمعنى آخر، تكون القطة بالنسبة إلى الملاحظ معلقة بين الحياة والموت حتى يتم رصدها. هذه النتيجة تتسم بالمفارقة، لكنها على الأقل تخص النتائج لتجربـة ذهنية (فكرية)، فإن انكسار القارورة هو موضوعيًا غير معين، وكذلك بقاء القطة

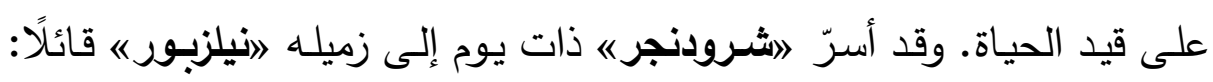

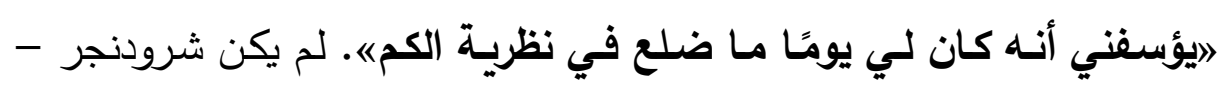
بالطبع - يندب مصير قطته الثـهيرة، لكنه كان يعلق على المعاني الخيالية الغريبة المتضمنة في فيزياء الكوانتم، هذا العلم المعني بدراسـة عالم الجسيمات دون المجهريـة submicroscopic particles مـن إلكترونـات، وفوتونـات،

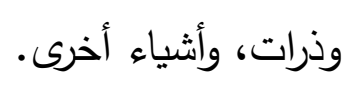

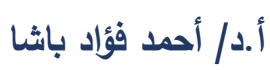
(خيال العلماء بين التعقُل والتصوُر) 


\section{مراجع للاستزادة:}

1- د. أحمد فؤاد باشـا، فلسفة العلوم بنظرة إسـلامية، سلسلة كتاب العربيـة

$$
\text { (130) (130)، الرياض 2013م. }
$$

2- و. أ. ب. بفروج، فن البحث العلمي، ترجمـة: زكريـا فهمي، مراجعة: د.

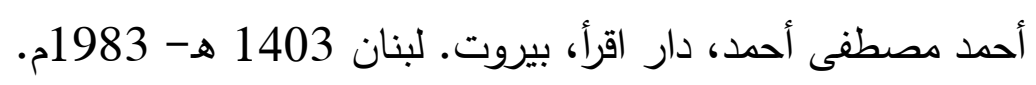

3- سام تريمان، من الذرة إلى الكوارك، نحو ثقافة علمية متقدمة لمواكبة علوم

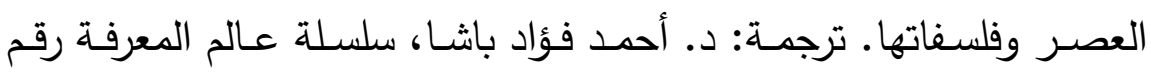

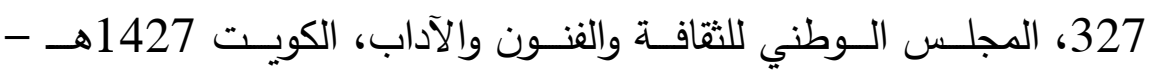

$$
\text { 2006 }
$$

$$
\text { 4- المواقع ذات الصلة على الثابكة الدولية (الإنترنت). }
$$

5- أعداد مجلـة العلوم الأمريكيـة، الترجمـة العربيـة، مؤسســة الكويت للتقدم

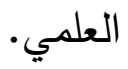

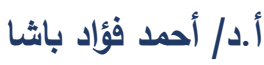

(خيال العلماء بين التعقُل والتصوُر) 